\title{
Retrospective study of marginal bone loss around two implants systems conducted by radiographic evaluation
}

Seoul Veterans Hospital, Department of Prosthodontics ${ }^{1}$ Seoul National University Dental Hospital, Department of Orthodontics, Emeritus professor ${ }^{2}$ Hee-Won Jang ${ }^{* 1}$,Young-II Jang ${ }^{2}$,Jeong-Kyung Kang ${ }^{1}$

Purpose : The aim of this study was to analyze the amount of marginal bone loss $(\mathrm{MBL})$ around implants and establish the difference between RBM and SLA surface.

Materials and Methods : 127 implants of RBM surface were placed in the posterior maxilla and mandible in 52 patients. 155 implants of SLA surface were installed in the posterior maxilla and mandible in 75 patients. Data were collected according to age, implant length, width and etc.

Clinical and radiographic examinations were performed during all procedure by one dentist.

MBL was evaluated on the base of three intervals i.e. at the time of loading( 0 year), and annually up to 1 year and 3 years.

Overdenture were excluded. And a gender of patients was male. Measurements to the nearest $0.01 \mathrm{~mm}$ were taken at the mesial and distal site, and the average values were calculated for each implant. R program(0.99.893 for Window 7$)$ was used, and OneWay ANOVA test was used to verify the significance of the mean MBL in RBM and SLA surface. The significance value was 0.05 . Two implants present internal connection, root shape and microthread(upper three threads).

It was Korean domestic brand(Dentis $\left.{ }^{\circledR}\right)$ which was similar to Astra implant with regards to appearance.

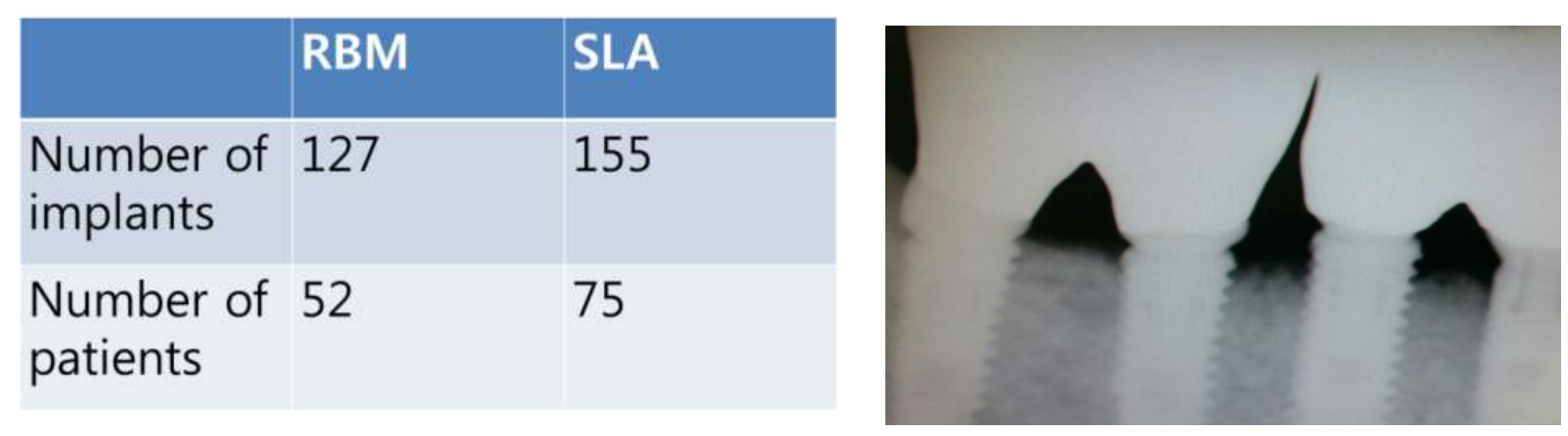

\begin{tabular}{|c|c|c|c|c|c|c|c|c|c|}
\hline RBM & diameter | & n & length & n & & diameter & n & length & n \\
\hline \multirow[t]{5}{*}{ RBM } & 4.7 & 83 & 12 & 72 & SLA & 6 & 2 & 12 & 99 \\
\hline & 4.3 & 30 & 10 & 53 & & 5.2 & 25 & 10 & 53 \\
\hline & 4.1 & 4 & 8 & 2 & & 4.7 & 83 & 8 & 3 \\
\hline & 3.7 & 10 & & & & 4.2 & 41 & & \\
\hline & & & & & & 3.9 & 4 & & \\
\hline
\end{tabular}

Results : A population of this study was consisted of all men with average age of 68 years. two of total implants failed after one month. One was RBM and the other was SLA.

1. The records of two implant systems at the baseline( 0 year) measurements were RBM $0.479 \mathrm{~mm}$ vs. SLA $0.132 \mathrm{~mm}$. There was statistically significant difference for annual bone loss.

2. The records of measurements at 1 year measurements were RBM $0.801 \mathrm{~mm}$ vs. SLA $0.424 \mathrm{~m}$. There was statistically significant difference for annual bone loss.

3. The records of measurements at 3 year were RBM $1.672 \mathrm{~mm}$ vs. SLA $0.844 \mathrm{~m}$. There was statistically significant difference for annual bone loss.

\begin{tabular}{|lllll}
\hline & RBM & SLA & df & P value \\
\hline 0 year & 0.479 & 0.132 & 277 & $2.2 \times 10^{-16 *}$ \\
1 year & 0.801 & 0.424 & 193.73 & $6.64 \times 10^{-42 *}$ \\
\hline 3 year & 1.672 & 0.844 & 193.14 & $1.37 \times 10^{-53 *}$
\end{tabular}
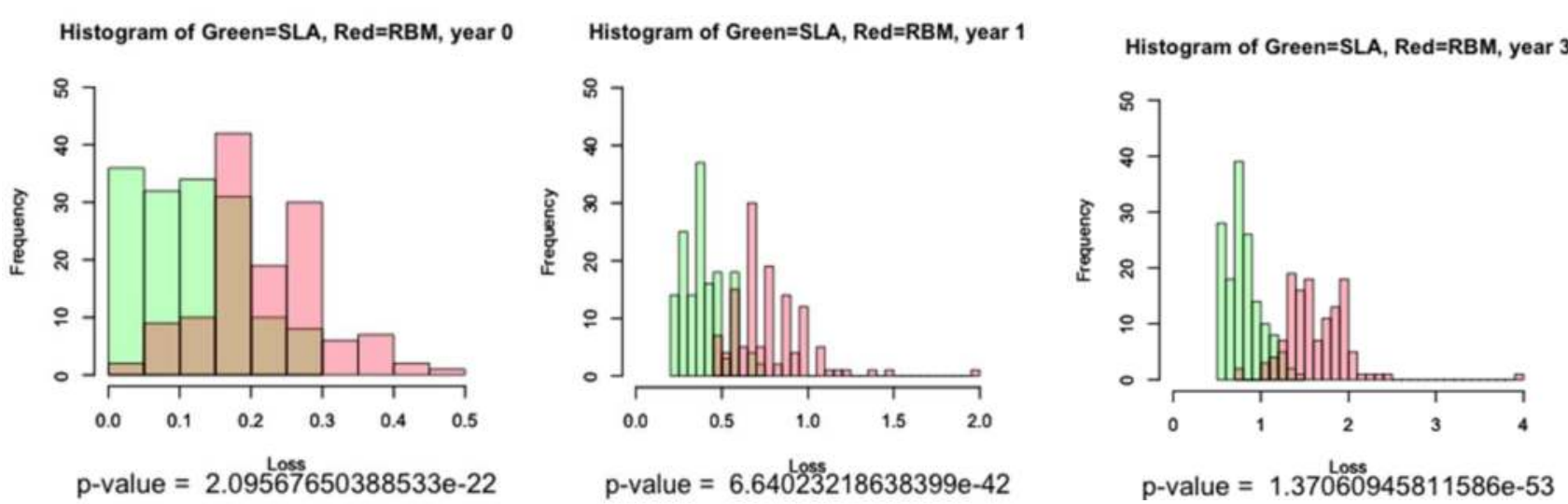

4. As the diameter became wider, the MBL of RBM was significant statistically. the MBL of SLA was not significant.

\begin{tabular}{llllll} 
RBM & df & Sq & MEAN Sq F value & P value \\
\hline diameter & 1 & 0.3671 & 0.36714 & 2.6477 & $0.03349 *$ \\
Residuals & 126 & 17.4716 & 0.13866 & & \\
SLA & df & Sq & MEAN Sq F value & P value \\
diameter & 1 & 0.0743 & 0.074333 & 0.7753 & 0.3804 \\
Residuals & 154 & 11.3133 & 0.095875 & &
\end{tabular}

5. As the length became longer, the MBL of RBM was significant statistically. The MBL of SLA was not significant.

$\begin{array}{lllllll}\text { RBM } & \text { df } & \text { Sq } & \text { Mean Sq } & \text { F value } & \text { P value } \\ \text { length } & 1 & 0.2752 & 0.27517 & 6.1906 & 0.01415^{*} \\ \text { Residuals } & 126 & 5.6007 & 0.04445 & & \\ & & & & & \end{array}$

$\begin{array}{lllllll}\text { SLA } & \text { df } & \text { Sq } & \text { Mean Sq } & \text { F value } & \text { P value } \\ \text { length } & 1 & 0.0412 & 0.04121 & 0.4286 & 0.514 \\ \text { Residuals } & 154 & 11.3464 & 0.096156 & & \\ & & & & & \end{array}$

Conclusion

1. As the time went by $(0,1,3$ year), the $M B L$ of different two surface showed different significance statistically.

2. As diameter became wider, the MBL of RBM reported different significance statistically. That of SLA showed no different significance.

3. As length became longer, the MBL of RBM reported different significance statistically. That of SLA depict no different significance.

\section{Reference}

1. J,Zweers. Clinical and radiographic evaluation of narrow- vs. regular-diameter dental implants: a 3-year follow-up. A retrospective study. Clin Oral Impl. Res. 26,2015,149-156.

2. Doris Burtscher. A 7-year prospective radiographic evaluation of marginal bone level around two different implant systems: a randomized clinical trial. Clin. Oral Impl. Res. 26,2015,1244-1249. 